What journalists retweet: Opinion, humor, and brand development on Twitter
2015, Vol. 16(7) 920-935

(C) The Author(s) 2014

Reprints and permissions: sagepub.co.uk/journalsPermissions.nav DOI: I0.1।77/|4648849|4550।35 jou.sagepub.com

\title{
Logan Molyneux
}

University of Texas at Austin, USA

\begin{abstract}
Using Twitter, journalists may pass along comment from other users without, at least ostensibly, taking accountability for that message. Minimizing responsibility and editorial oversight, as is the case with retweets, allows a different view of individual journalists as gatekeepers. Through a qualitative textual analysis, this study finds that journalists are challenging norms of objectivity and independence on Twitter. Journalists frequently pass along subtle interpretation and analysis rather than strong opinions. Many retweets are humorous, sometimes even at journalism's expense. Journalists also retweet many messages about themselves, working to build a personal brand and relationships with their audience. Implications for journalists, their industry, and the audience are discussed.
\end{abstract}

\section{Keywords}

Branding, gatekeeping, humor, journalism practice, norms, objectivity, social media, Twitter

Journalists' role in shaping history's first draft comes into sharp focus in the age of Twitter, where millions of brief messages are exchanged each day and where many of the day's most important stories begin to take shape. Journalism and Twitter have a unique, compelling relationship where the affordances of the medium meet journalistic needs and journalists are well positioned to provide the constant flow of updates that Twitter thrives on. Because of this and other digital media innovations, the news landscape is now one of information exchange (in addition to broadcasting), calling for new understanding of journalists' position as stewards of public information.

\section{Corresponding author:}

Logan Molyneux, School of Journalism, University of Texas at Austin, 300 W. Dean Keeton, Austin, TX 78712-1073, USA.

Email: logan.m@utexas.edu 
Not well explored, however, is how journalists act in their role as 'less of an authority and more of a guide' (Nolan, 2003). Most studies of journalistic output focus on the finished product, often heavily edited. But one of Twitter's features - the ability to 'retweet' or send along messages from other users, either wholesale or with additional comment offers a different view of what journalists consider to be worth passing along. This study attempts to tap into that informational exchange, as stories are developing, and examine qualitatively what journalists retweet.

Retweets were chosen for this study because they offer a view of a new way in which journalists act as gatekeepers, exercising their judgment in curating Twitter's stream of information. Previous studies of journalists on Twitter have been quantitatively focused (for a few recent examples, see Bekafigo and McBride, 2012; Larsson and Moe, 2011; Mascaro and Goggins, 2012), with relatively little qualitative work (Lawrence, 2012). This study takes a qualitative approach, conducting a textual analysis of journalists' retweets from the 2012 US political conventions, which allows a more in-depth, contextual look not common in the current literature on the subject. One goal is to broaden researchers' understanding of news content on Twitter by inductively building categories from the content observed. This study also aims to improve understanding of journalistic norms and the press' role in the election process and democracy. A review of gatekeeping and normative theories is presented, followed by a discussion of the nature of retweets and Twitter. Methods and results are presented, finishing with analysis and discussion.

\section{Journalists and gatekeeping}

Journalists were once thought of as the primary gatekeepers of news, selecting various processes through which bits of the latest intelligence were passed on to the public. $\mathrm{Mr}$ Gates, the classic example of a wire editor, spent his evening deciding which reports to include in the morning paper (White, 1950). Researchers have since broadened their focus to include a range of external factors that influence any single journalist's decisions, including professional, organizational, social, and cultural influences (Shoemaker et al., 2009). The advent of the Internet led observers to further downplay the gatekeeping role of individual journalists. Because there were now so many conduits through which to receive information, the notion that only journalists may act as a network of gatekeepers, selecting and ordering piles of information into nuggets of truth, is 'increasingly problematic - or even obsolete' (Kovach and Rosenstiel 2010: 171).

While it may be argued that, given an abundance of information sources, the value of any one of them is diminished (e.g. Williams and Delli Carpini, 2000), the fact remains that individuals still make decisions about what to pass on to others - gatekeeping decisions, at their simplest. In fact, the prevalence of social media, which foster connections among individuals, may be effecting a shift in the locus of journalistic gatekeeping (Hermida and Zeller, 2014). Individualized social media accounts have given journalists the opportunity to connect with their audiences directly, cultivating followings and relationships (Enda, 2011; Farhi, 2009; Lavrusik, 2013; Molyneux and Holton, 2014). This puts the journalist in a different gatekeeping position - people turn to journalists on Twitter as curators or guides in the sea of digital information. Where Mr Gates observed a stream of information coming across the wires and selected which bits to pass on to his 
audience, today's journalists treat Twitter as the news wire (Lawrence, 2012) and select which bits to retweet to their followers.

In this setting, external influences on gatekeeping decisions are arguably less important than internal (or individual) influences. This is the case because news organizations' social media policies are underdeveloped, at best. At the time this study was conducted, there were few reports that news media organizations were overseeing individual journalists' Twitter feeds (usually after a breach of conduct), and this was the exception rather than the rule (Sonderman, 2012a, 2012b). A more recent review of news companies' social media guidelines found that there is no unified approach and that what guidelines do exist are widely despised by journalists (Opgenhaffen and Scheerlinck, 2014). In the absence of strict rules, journalists have some room to experiment, and this study investigates what journalists on Twitter are choosing to pass along.

\section{Changing norms}

Earlier gatekeeping studies interviewed journalists or examined their work environments to understand the motives and influences behind their decisions. This study looks only at the results of journalists' gatekeeping decisions, the bits of information they selected to pass along. Still, now that there is several decades of understanding of what journalists typically consider newsworthy, the question becomes whether journalists on Twitter follow those patterns.

Research suggests that journalists' behavior on social media sometimes sticks to traditional norms (Arant and Anderson, 2001; Lasorsa et al., 2011), but more often breaks with them. Some old practices from traditional media carry over, and others are challenged in the new media space (Singer, 2005). In a social media setting such as Twitter, at least two traditional journalistic norms may be challenged by emerging journalistic practices.

The first is objectivity. Since at least the turn of the 20th century, journalists have held fast to the objectivity norm - that is, a sense that journalists must report only the facts, setting aside their own opinions on what they cover (Kovach and Rosenstiel, 2007). In order to achieve this objectivity, journalists often avoided personal involvement, especially in politics. Social media, however, take down the curtain by allowing both sources and readers to interact with the journalist. This is part of a larger, digital-age trend. Having access to information has empowered the audience, and some observers now call objectivity 'the view from nowhere' (Rosen, 2006, 2010). Previous research on Twitter (Lasorsa et al., 2011; Lawrence et al., 2013) suggests that objectivity is difficult to achieve there as reporters develop an online persona and tweet information as it becomes available (rather than waiting for comment from the 'other side').

The second behavior, interacting with the audience, is closely related. In part because of the objectivity norm, but more as a show of independence (Kovach and Rosenstiel, 2007), journalists are traditionally advised to keep their distance from sources primarily, but also from any other forms of influence. Participating in social media does not easily accommodate such a detached position, and journalists have more often been seen reaching out through digital media rather than being recluses. Perhaps because of this, some scholars view journalists' activities online as focusing on relationships, taking advantage of the medium's social affordances to connect with audiences (Singer, 2006; Vivo and 
Manuel, 2013). Singer noted that reaching out to the audience was not embraced by all journalists, but many now report seeing it as their duty not just to report the news but also to connect with audiences and cultivate relationships (Molyneux and Holton, 2014). Journalists' uptake of social media, if somewhat uneven, has at least challenged journalistic norms of objectivity and independence.

In short, journalistic best practices on Twitter are still developing (Hermida, 2013). This qualitative look at journalists' retweets, then, expects to observe a different form of gatekeeping - one still influenced by individual tastes, idiosyncrasies, and journalistic norms, but one also stretching to incorporate audience preferences and social media norms.

\section{Journalists and retweets}

There seem to be two schools of thought among journalists regarding their retweeting behavior. Among themselves, or when discussing best practices, they frequently caution against retweeting anything that might reflect poorly on themselves or their organization (Opgenhaffen and Scheerlinck, 2014). This, they say, is because people do not readily separate retweets from original tweets - both come from the same journalist and therefore are associated with that journalist. This promotes a sense of caution, a sentiment presumably intended to please supervisors more than the audience. On the other hand, in the short bios on their Twitter profile pages, journalists frequently advise followers that 'retweets are not endorsements', perhaps hoping this disclaimer will protect them if their better judgment ever fails to. This would seem to free them to retweet whatever they wish because the information can be easily traced to its original source, absolving the journalist of responsibility. Clearly, this is not always the case because Twitter allows tweets to be sent along wholesale or to be passed along with a comment appended. If a comment is appended, it is often an endorsement of the original tweet, presumably overriding the disclaimer.

These two approaches are used differently by different journalists. Given that social media journalism is still a realm of experimentation, there is no unified approach. The contribution of this study is to examine journalists' retweets as evidence of their gatekeeping and norm-keeping behavior in order to learn what they find important enough and safe enough to pass along to their followers. This insight into their judgment informs our understanding of a decentralized, networked form of journalism and gatekeeping where individuals are the key players.

From the public's perspective, any journalist is one voice among many. For this reason, this study focuses on a moment in American political life when the public's reliance on journalists with access is heightened: the party conventions, generally seen as the beginning of the US presidential election campaign. The conventions occur over the course of several days, with activities all day long; only the most important of these are broadcast to the public. To learn what else is going on there beyond marquee speeches, the American public must rely on those politicians and journalists who have been granted access to the event.

In this setting, individual journalists are likely the most powerful factor in deciding what the Twitter audience sees. On Twitter, journalists may be seen as well-connected individuals in a position to control the flow of information (Jürgens et al., 2011). The political journalists who are at the convention, because of their access, act as the public's window 
into the convention's happenings. These journalists are then key nodes in the network, disseminating information about the conventions, and what they choose to pass along to their followers has a relevant impact on the information they receive about the convention.

But even individuals who are not already hubs of conversation can shape a discussion and produce highly replicated tweets when they produce them in volume (Bastos et al., 2013). Journalists, who are known to monitor Twitter for indications of activity around potential news interests (Lawrence, 2012), are in good position to pick up on this activity and be part of spreading it to a wider audience. For this reason, it is important to study what drives journalists' gatekeeping decisions when retweeting and to understand what they noticed in their scanning that they felt was worth passing on to their followers.

\section{Research questions}

The objectivity norm is tied to gatekeeping by the thinking that operating the gates properly will result in objective news reports (Singer, 2005). As journalists keep the gate, it is conceivable that they would continue to follow established practices on Twitter, passing along other objective reports and discussing the political horse race from a distance, as usual (Capella and Jamieson, 1997; Iyengar et al., 2004). Or it may be that journalists have adopted different practices as they adapt to using the new medium. By examining retweets, when journalists have the least incentive to adhere to journalistic norms, it is possible to obtain a view of what may be coming down the pike, so to speak, as new norms are developed and adopted by journalists on Twitter.

This study therefore poses the following two research questions:

- How do journalists keep the gates on Twitter?

- Given what journalists retweet, how are norms of objectivity and audience interaction evolving?

\section{Method}

This study used a custom-built software program that collected data from Twitter every 15 minutes and saved it to an archive. Tweets were collected from a purposive sample of 430 campaign journalists in the United States during the height of the 2012 presidential campaign season (Lawrence et al., 2013). ${ }^{1}$ A qualitative analysis of such a large dataset was not possible, so this study focused on eight journalists carefully selected to represent the broader sample. Schultz (2007) proposes that journalists share an economy of editorial capital with those having more experience or in hierarchical positions having more influence on other journalists. For this reason, the journalists selected for this study were among the top 20 most frequent tweeters ${ }^{2}$ (in the overall sample of political journalists) during the two national conventions, Democratic and Republican. A simple cut at the top of the list (say, the top 10) was impractical because the top tweeters were different in each convention. Additionally, it was necessary to look further down the list in order to include media of all types and reporters with different assignments. The busiest tweeters were most often from online outlets such as POLITICO and BuzzFeed, but a sample including only those journalists is not likely to represent the broader field of journalists. 
Table I. Journalists in purposive sample.

\begin{tabular}{lllll}
\hline Name & News outlet & Description & $\begin{array}{l}\text { Retweets in } \\
\text { sample }\end{array}$ & $\begin{array}{l}\text { Total tweets at } \\
2012 \\
\text { conventions }\end{array}$ \\
\hline Zeke Miller & BuzzFeed & Political reporter & 310 & 1785 \\
Dave Weigel & Slate, MSNBC & Political reporter & 263 & 742 \\
Alex Burns & POLITICO & Political reporter & 262 & 671 \\
Dana Loesch & Talk radio, CNN & Radio host, commentator & 228 & 885 \\
Jonathan & The Washington Post, & Opinion writer & 158 & 860 \\
Capehart & MSNBC & & & \\
Sally Kohn & FOX news & Writer and commentator & 113 & 782 \\
Peter Baker & The New York Times & White House correspondent & 56 & 188 \\
Chris Cillizza & The Washington Post & Political reporter, blogger & 55 & 1007
\end{tabular}

By including a range of media types, political orientations, and assignments, the sample is composed of those with a range of 'editorial capital' whose influence conceivably extends across the broader sample of political journalists. The journalists selected for this study are included in Table 1.

Overall, these eight journalists sent out more than 6800 tweets during the two conventions combined. This study focused only on what these journalists retweeted, found by searching for the characters the Twitter application programming interface (API) uses to signify a retweet. There were 719 retweets collected during the 4 days of the Republican National Convention and 726 retweets collected during the 4 days of the Democratic National Convention (DNC), for a total of 1445 retweets from the eight journalists. This includes standard retweets (including those posted manually using the retweet signifier and those using the automatic retweeting function now build into Twitter) and also retweets with comment (retweeting another person's message with a comment appended). It does not include any of the journalists' original tweets or any conversational 'mentions' to or from the journalists' Twitter contacts. As such, the results presented hereafter are meant to illuminate journalists' behavior and decision making when selecting information to pass on to their audiences, rather than characteristics of Twitter or of its use by journalists. While the medium itself may exert some influence on journalists' behavior, enabling normative shifts, it cannot be treated as sufficient cause for these shifts. Instead, Twitter is treated here as a useful arena for studying journalists' gatekeeping decisions because it allows them to make these decisions with greater autonomy and with less risk compared to their edited and published or broadcast work.

This study conducted a qualitative textual analysis on these retweets, looking for patterns and departures from traditional journalistic norms. Textual analysis is distinct from its quantitative counterpart, content analysis. A key difference is the ability of textual analysis to look beyond manifest content and include analysis of subtext, context, and assumptions (Fürsich, 2009). Fürsich notes that textual analysis of media messages is especially appropriate because media content represents a unique moment between encoding and decoding of the message. In a textual analysis, then, the researcher acts as the decoder during a long immersion in the text. Textual analysis proceeds without an a 
priori identification of what one might find or what to look for. This method is particularly appropriate here considering that norms and gatekeeping practices on Twitter are still forming, and there may not be indications in the previous literature of what to code for. A qualitative analysis is the first step in the process of identifying trends and establishing directions for future research.

The approach here, therefore, was to look for recurring types of retweets and sources and to identify what kinds of things journalists tend to retweet, inductively building categories following grounded theory methods (Lindlof and Taylor, 2011). While reading every retweet from the Republican convention, several were marked with preliminary codes and annotations. These notes were developed and synthesized into more focused codes signifying some of the patterns already observed, and then all the retweets from the Democratic convention were read. Codes and memos were made as appropriate. No new categories emerged after examining the Democratic convention, but all the existing categories were developed and sharpened. For example, many tweets during the Republican convention were funny, so they were marked with a humor code. As the textual analysis progressed, it became apparent that there was a distinction between passing along someone else's joke and the journalist making his own joke. This more subtle distinction could then be coded and analyzed.

\section{Findings}

First, some words about the sample overall. The two newspaper journalists, Chris Cillizza and Peter Baker, retweeted the least of the eight journalists studied and also were the most staid in their approach. They tended to pull retweets from a narrower range of sources (including many official sources), and their retweets steered clear of the crass or controversial. This result is not surprising, perhaps, considering that newspapers have been considered (and consider themselves) elite bastions of American journalism, guardians of all that is traditional and established. In fact, this has frequently been used against them as a criticism as they struggle to adapt to a changing news environment without a regular news cycle or a reliable business model. That being said, the newspaper journalists' approach was more similar to that of the magazine, online, and television journalists in the sample than it was different. They still fit within the overall patterns described below.

Almost all retweets were narrowly focused on politics and the conventions, conforming to the expectation that the conventions are a time of focused coverage and gatekeeping. At first glance, this is a logical observation; but consider that Twitter is designed as a social medium and is sometimes criticized as containing only inane babble (in fact, the standard joke is that Twitter is full of people posting what they had for lunch). Only a handful of retweets in the entire sample were about something entirely aside from national politics. They were not retweeting information about sports, family, or other personal interests. This may be because the conventions are a time of highly focused political activity, and most journalists covering them are away from home and their normal routines. Everyone is in one place doing one thing, and there is little political action elsewhere. But it is worth noting that these journalists used their Twitter accounts almost exclusively for work purposes (Lawrence et al., 2013), from sunup to sundown and often beyond. Another possible explanation is that these journalists, the most frequent users 
among political journalists, keep their tweets focused on work to cultivate a specific following. They may even be working under organizational policies to this effect.

Furthermore, the sources that journalists retweeted were often other journalists. In fact, even the small sample of journalists analyzed in this study sometimes retweeted each other. Outside voices were included, however, although these were commonly informed observers, judging by how well their comments tracked with the others in the sample. Somewhat rarer were retweets from seemingly average followers, asking questions or interacting with the journalist. Retweets from the non-politically informed were commonly attempts at humor or interactions with the journalists themselves.

Perhaps the most striking characteristic of the retweets studied was that few of them are what would normally be considered news (except in the case of Zeke Miller, who did share a good number of headlines along with the blow-by-blow comings and goings at the conventions). Very few of them could be read as a headline, a news story in itself, or a reference to a finished news product. Headline tweets such as 'RT@marceelias: Three judge panel of DC Court throws out Texas redistricting plan' represented only the smallest minority of retweets. Rather than following a headline model, informational retweets included only factoids or information sources that would likely become part of a larger news story later on. Examples of these factoids include retweets such as 'RT @nationaljournal: Read a full transcript of the first lady's speech http://t.co/OywbVrOU' or 'RT @ TPElections: POLL: Obama leads Romney 50\% to 46\% in Florida'. These are not complete news stories in themselves, but news snippets that fit the information shotgun of Twitter. Again, these informational tweets were among the minority of all retweets in the sample, and they were often snippets rather than fully developed news stories. So, if journalists were not retweeting news most of the time, what were they passing along instead?

\section{Less news, more opinion}

Journalists have been observed in earlier studies dabbling in opinion on Twitter (Lasorsa et al., 2011; Lawrence et al., 2013), and this is even more the case when only retweets are considered. A large portion of retweets contained opinion. It is true that about half the sample were journalists identified as columnists or commentators, but even those identified as straight reporters engaged in sharing opinions of the types described below, if sometimes to a lesser degree. The opinions journalists shared (as presented in the examples below) were commonly about the candidates, their parties, and their campaigns. They frequently opined about speeches, but also about votes and actions taken at the conventions. This tracks with the convention-centered focus described earlier. Journalists also offered opinions on media coverage of the conventions, reflexively criticizing themselves and their colleagues (often, for working too much as a pack or drooling over insignificant developments). They also shared opinions about convention organization, including difficult weather, over-zealous security measures, and planning for speakers and presentation.

Opinions were not the strong arguments found on an editorial page. Rare was the direct, overt opinion such as this from Cillizza, adding his own endorsement to someone else's statement: 'This is also true. RT @eamon1916: “Clinton speech > Any speech in the last 10 years"'. A minority of retweets passed along such strong opinions, even without endorsements, such as this from Weigel, 'RT @joshgerstein: Sadly, Dems have 
devalued convention voting process with yesterday's farce \#skipit'. Some of the retweets included cheerleading (such as this from Loesch, 'RT @Reince: Truly inspirational story from @MiaBLove, Utah's next Congresswoman. We need her in Washington!'), but again, this was the minority.

Usually, the retweets contained subtler forms of analysis, interpretation, commentary, and context. Alex Burns retweeted this during Michelle Obama's speech at the DNC: 'RT@andysere: she seems really proud of this country. almost like it's the first time she's felt that way'. Later, he sent along this take on network TV's news judgment: 'RT @jonathanchait Networks aren't showing Fluke speech. This is still part of the base convention, not the general audience convention'. Peter Baker retweeted this contextual placement and paraphrase of Michelle Obama's speech: 'RT @jodikantor: In 2008, Michelle Obama also did men-don't-understand-women-have-it-harder'. Sally Kohn retweeted this reaction mixed with a quote 'RT@jljacobson: RT@Ziggy_Daddy: .@ BarackObama: "Four years ago, I promised to end the war in \#Iraq. We did." \#AreYouBetterOff? Yes!' There was a mix of speculation and humor, such as this, retweeted by Chris Cillizza: 'Ouchy. RT@michaelscherer Martin O’Malley may turn out to be the Tim Pawlenty of the Democratic Party'.

The prevalence of opinion and the absence of news in journalists' retweets may be explained by a couple of factors. First, journalists likely reserve their original tweets for spreading news. These data analyzed here cannot confirm this suggestion, but there is some evidence to support it. For instance, the newsy things journalists did retweet were most often from other journalists, including some in this small sample. At least in some ways, the top of the political journalism world on Twitter is a small world (Jürgens et al., 2011). Also, this follows the journalistic tradition of wanting to get the story first and exclusively. Even in traditional news media, journalists choose to report their own stories rather than repeating (or retweeting) those of another news organization. When one news organization has an exclusive that others wish to pass along, they are at pains to hide that it came from somewhere else, using wording such as 'reportedly' and 'news reports said', often without naming the original organization. On Twitter, journalists may simply refrain from retweeting news, choosing instead to send along bits of opinion that they would not be expected to have in their news stories anyway.

Second, journalists' main reports are expected to be free of opinion according to the objectivity norm, and many go to great lengths to ensure their neutrality. Retweets, on the other hand, are a space where journalists may feel more at liberty to pass along opinions. Although they take care to note, in their bio on Twitter or even in tweets responding to other users, that 'retweets are not endorsements', the journalist's Twitter followers may or may not make a strong distinction between a journalist's main voice and the array of other voices he or she chooses to retweet. In this way, Twitter affords the journalist a bit of a curtain to hide behind, allowing them to pass along opinions without the accountability and threat to their objectivity that would come if they stated those same words themselves. If journalists take advantage of this, they are able to engage in some muchsuppressed self-expression without responsibility or fear of censure. Of course, the strongest opinions are left out as those may be most likely to bring on managerial editing - as when The New York Times decided to edit the social media posts of its Jerusalem bureau chief (Sonderman, 2012b). But so long as journalists stay away from what is most 
controversial, they may be able to carve out a space in which they can experiment with opinion without claiming it as their own. Even so, they proceed with some trepidation, eschewing strong, overt opinions in favor of providing subtler analysis and context.

\section{Journalists love a good joke}

A second significant pattern in retweets is a preference for humor. Fair warning: these tweets may not make you guffaw and slap your knee, but they can at least be identified as an attempt at humor. Some of them are funny only in context of the conventions or the speech happening at the moment, which is the journalists' world at the time. Much of that is lost here, but the examples that follow still speak to the observed trends. Again, it is not the presence of humor, which has been observed before (Holton and Lewis, 2011), but its character on Twitter that is most revealing.

Sometimes funny tweets are passed along on their own merits. Kohn retweeted this on the DNC's last day: 'RT @aterkel: Foo Fighters performed. Jared Leto spotted in the halls. Everyone's talking abt Bill Clinton. Feel like I'm in high school'. Cillizza seconded (or one-hundreded?) this one, a rare off-topic post: ‘+100 RT @mollykord: I hate joggers who jog in place at a red light. It's a time out from God. Take it'. Many of the jokes were about the candidates or their comings and goings, such as these two from Burns: 'RT@wise_kaplan Mitt: Saved the Olympics. Newt: Watched them. Vote Newt'. And this, referring to Mitt Romney: 'RT @CommsDirector: Dear world: WMR is going to Tampa to join his wife onstage after her remarks. Not exactly a shocker'.

Other times, an otherwise mundane tweet is sent along with a snarky comment by the journalist. Weigel made this joke: "He was voted "most likely to lose breath" in high school. RT@BuzzFeedAndrew: Does Reince Priebus always sound like he’s out of breathe?' Some of these jokes are at the expense of colleagues, like this one from Burns identifying some non-news: 'HMMMMMM RT @EmilyABC Romney will be in Tampa tomorrow, the same night his wife Ann will take the stage'. Also, self-deprecating humor was common, such as this crack from Weigel: 'If you see him, punch him RT @danhedonic: Pretty sure I spotted either@daveweigel or a lookalike at RNC google lounge'. Miller tied this one into journalists' work by using a hashtag: ‘\#reporterproblems RT @ kasie: And by tomorrow, I mean Wednesday. Which is, technically, today'. Frequently, they make fun of the Internet, the very thing that they are all clearly addicted to (whether by choice or job necessity). This retweet from Weigel came shortly after the joke about Priebus being out of breath: 'RT@BuzzFeedAndrew:@daveweigel@nolesfan2011 These 21 GIFs of Reince Priebus breathing will restore your faith in his breath'. And here's another from Weigel on Day 1 of the RNC: 'Dude I instagrammed a convention badge!!!!!1111!!! RT @drgrist: Hello, internet. I did not miss you’.

Part of this is journalists playing to the atmosphere on Twitter. The form of the medium itself, with its short 140-character posts, lends itself to punch lines and comedic asides. Furthermore, the Internet in general and Twitter specifically have been a forum for humor (Shifman, 2007), with such fake Twitter accounts as @BPglobalPR, purporting to provide info from the oil giant's efforts to smooth over the gulf oil spill, and @bronxzoocobra, supposedly written by an escaped snake loose in the Big Apple. In fact, one commonly retweeted account in the humor category was@wise_kaplan, who pretended 
to be a Newt Gingrich supporter but in fact just cracked jokes. 'RT @wise_kaplan Like Pizza? You'll love Newt. Gingrich 2012', and so on (also see above). If Twitter is a forum where snark, cynicism, and humor are the rules of the game, these findings suggest that journalists have adapted by employing those tools themselves to fit in.

But another part of the humor trend is that journalists may crave such an outlet, much in the same way that they have with opinion. Many journalists are, by nature, witty writers who love a turn of phrase, keen observers with an often cynical eye. They are effortlessly familiar not only with the language but also with the political activity they cover, and that proximity to those in power affords them opportunities for humorous observations on how the country is governed. Their work brings them to where the sausage is being made, as the metaphor goes, which is inherently messy and potentially a rich source of humor - only journalists cannot normally take advantage of such opportunities in their traditional role as objective observers. So, not only does journalists' nature mesh well with the snarky attitude so prevalent on Twitter, they may appreciate Twitter as an outlet that lets them do what they feel they cannot in a traditional news environment - make jokes about the political process.

\section{Personal brand development}

Some journalists use retweets as a way to establish a personal brand. This is an aspect of journalistic practice that is still emerging, both in practice and in the academic literature. Like the patterns described above, this is something that is likely accelerated by social media because of the affordances they provide. This section explains what elements of brand development and self-promotion were observed in the sample and then explicates what factors make up the concept of personal brand development so that this idea may be incorporated into future studies.

The simplest form of personal branding is direct self-promotion. Journalists frequently tweet links to their own stories and those of other journalists (Lawrence et al., 2013). They also retweet other people's links to their stories as a third-party endorsement of their work. Cillizza retweeted someone who had linked to a story of his: 'RT @, FixAaron: Breaking: Gabrielle Giffords launches Gabby PAC - The Fix http://t.co/ kdQuQ2eb'. All journalists engaged in this type of self-promotion, sending along links to their own work and noting times when they would be on the air. They also frequently promoted their colleagues from their home news outlet, as Baker does here: 'RT @ thecaucus: What Ann Romney will say during her RNC speech http://t.co/8OzUEPhp'. Although this behavior certainly happens in the journalists' own voice (in their tweets), they also use retweets as a way to toot their own horn.

Some self-promotion is obvious and expected, but brand development goes beyond spreading links to one's stories. A smaller group of journalists, including the opinion columnist Capehart, the TV commentators, and Slate journalist Weigel, spent much time retweeting what others said about them. Many of their retweets were about themselves, though not in their own voice. The journalists retweeted messages sent to them, about them - personal interactions that they chose to share with the broader public. These interactions took two main forms. Journalists frequently retweeted hate mail they received on Twitter and also retweeted praise and other 'love letters' sent by their followers. Here are some examples of hate mail retweets during the DNC: 
- RT@MeetTheSupremes: @DLoesch is a poor excuse for a human.

- RT@KrisandBugachi: @daveweigel OK, you've made your point. You'd actually made it several hours ago. Move on please.

- RT@Penswordman: @sallykohn Why are you so bitter and ugly? // because I read tweets like yours ...

And some love letters, from the same convention are as follows:

- RT@toddstarnes: Just had a wonderful conversation with my neighbor @sallykohn - a very nice lady!

- RT@EvanPokroy: The advantage of being stuck at work? Get to watch the DanaCam@DLoesch

- RT@Toure: @CapehartJ Looking forward to having you on The Cycle tomorrow!//me, too! Thanks.

Telling people you were praised makes some sense. But why would a journalist open their hate mail in public? Maybe any publicity is good publicity. Also, journalists' conversations about themselves are best understood as a show of independence and their resilience to criticism. Rather than promoting themselves directly by taking a marketing or advertising approach, they pick tweets from others that fit the brand they want to develop and then pass those along to their followers. They may show, in the case of hate mail, that they are not bothered by being called a crazy conservative or a radical liberal. They may show what qualities others recognize in their work. The conversation about the journalist himself is curated and then presented to a broader public to develop a personal brand. This is a new kind of transparency that is not presentable in a string of news reports the journalist files. This type of job talk breaks down the fourth wall between the media and the audience and increases intimacy, essential in developing a personal brand.

The journalists observed commonly engaging in this activity are those most likely to need to have a personal brand. That is, Capehart's columns are only as valuable as Capehart or his reputation as a columnist. Most reporters for traditional news outlets are not known by name to the general public, despite their bylines. People view general interest news as having been reported by The New York Times, rather than by Peter Baker. But the columnist and commentators fill a different role in the journalistic conversation about politics, where they must make observations and act as opinion leaders. Still, Dave Weigel, who identifies himself as a 'political reporter', followed the same trends as did the columnist and commentators.

This use of Twitter, like the others mentioned above, is again likely an outgrowth of one of the medium's characteristics. That is, journalists promote themselves because they now have a direct connection to an audience to whom they may promote themselves. Because their tweets are not (yet?) subjected to the layers of editing and filtering that finished news products are, they are able to carve out a spot for themselves. It is not clear why journalists choose to create a personal brand on social media. Possible explanations include that it is a capitalistic endeavor whereby they position themselves for jobs after their current one, or even to become a valued voice themselves, independent of their news organization. Alternatively, it may be narcissistic, fueled by a simple, human desire for attention.

Personal branding, then, may be described as follows in order for it to be useful as a theoretical construct in future studies. Personal branding on Twitter includes any tweet that 
is self-referential, be that a notice of an upcoming television appearance, a link to one's own story, or positive or negative discussion of oneself. Self-referential tweets and retweets may be easily identified by searching for the journalist's Twitter handle, name, and personal pronouns (though this broader net would catch some tweets and retweets that are not actually the journalist referring to himself or herself). Self-referential tweets may be classified into two sub-categories. Hate mail and love letters could be coded separately, as done in this study, or they could be collapsed into a singular category of personal mail, defined as reviews of the journalist or his or her work. A second category within the self-referential umbrella would be promotion, defined as links to or mentions of one's own work. This category may appear to overlap with the conception of 'job talk' used in other studies (Lasorsa et al., 2011), but the distinction is that job talk deals with the nuts and bolts of a journalist's newsgathering work, the daily grind, or the incremental advances that lead to a finished product. Promotion, on the other hand, most often deals with a finished product or, if not, a product or appearance that will be presented soon. Other types of self-referential tweets (such as the self-deprecating humor observed in the sample) were infrequent enough not to merit their own sub-category. Together, these concepts may help define personal branding in textual or content analysis of Twitter.

\section{Summary and conclusion}

On Twitter, journalists challenge the objectivity norm by retweeting a modicum of news and instead pass along a mix of opinion, humor, and personal branding. The content of these tweets appears to be driven more by a desire to form relationships with their audience than by journalists' work in information gathering. These findings shed light on journalists' gatekeeping decisions, which in this case seem to be influenced more by personal tastes and interests than by organizational or institutional norms. These findings add depth and definition to already observed trends of journalists using humor, opinion, and branding as they embrace social media. The results from this non-representative sample are not intended for generalization; however, given the selection methods outlined earlier, it is reasonable to consider these results indicative of how other journalists might be acting as they embrace Twitter. The findings described here are heuristically useful as they clarify substantive and qualitative dimensions of opinion, humor, and branding in journalistic decision making.

These findings also reveal a range of decision making practices as journalists keep the gates on social media. There were some common themes observed that may apply to other social media, such as Facebook, as well. First, journalists find it important to pass along opinions about the subjects they cover. These subjects are the very ones they are expected to remain objective about, suggesting that traditional norms may hold less sway in journalists' gatekeeping decisions. Journalists appear to make decisions based on blending in with the social media crowd and on their own self-interest. Even sharing opinions and jokes can be viewed as an attempt to create a public-facing image, an effort that becomes more direct with the branding practices observed here. And as new norms take hold on Twitter, they may spread to other aspects of journalists' work. If journalists' gatekeeping decisions do become self-interested, journalists put at risk the very quality - news judgment - that separates them from other writers and observers. 
For journalists, it is time to re-evaluate their role as individuals interacting with a newly active public. Journalists have long been cogs in a bigger machine, as evidenced by many observers referring to 'the media' as if they were a single voice. Now that journalists have a direct line to their audience, they have begun to act differently than they would in other news arenas, perhaps making it more difficult to maintain independence. Their focus is still the news, but they are taking on different roles - commentator, heckler, interpreter, marketer, and so on. As journalists negotiate this new space, they must decide what is most important for them and for their profession, and unfortunately, those two questions may each have different answers. Looking to traditional norms may not be the best answer, and in fact journalists should be encouraged to use this direct line to the public to elicit feedback on what is working and what is not. In this way, they can work with the audience in developing new newsgathering practices that best serve both the gatherer and the consumer.

The news industry faces some tough questions in light of these findings. Individual voices are clearly emerging and are being promoted as individuals (rather than agents of a news organization). News outlets and institutions will have to consider whether such promotion helps or hinders their own goals. It may be that the post is helped by having a famous individual journalist on staff. Or it may be that the famous individual begins to detract from the company's core product by drawing too much attention to himself or herself. Furthermore, journalists whose work is in demand will be in demand by other media outlets, hoping to burnish their own portfolios.

News companies may need to proceed with caution, however, as there may be a point where a journalist has developed enough of a personal brand that the benefits of independence (and its difficulties) outweigh the benefits (and difficulties) of being part of a larger organization. Some journalists (famously, Ezra Klein, for example) have already broken away from their parent organizations to begin their own ventures. In other words, news organizations, though meaning well, could end up driving away their most valuable journalists by imposing too many restrictions.

Among the public, there may be winners and losers as a result of these developments. There is certainly some value in hearing more opinion and interpretation from those observers closest to the political process in a democracy. The public may be seen to benefit from any additional journalistic output as it contributes to the overall body of intelligence about the government. On the other hand, an oversupply of one kind of information (in this case, perhaps, opinion) creates a scarcity of demand for it. Social media present an opportunity for journalists and their audience to engage in a public conversation about what is important to cover, a set of gatekeeping decisions in which both groups must be keenly interested.

\section{Declaration of Conflicting Interests}

The author(s) declared no potential conflicts of interest with respect to the research, authorship, and/or publication of this article.

\section{Funding}

The author(s) received no financial support for the research, authorship, and/or publication of this article. 


\section{Notes}

1. For more information on what this overall sample contained and how it was drawn, see Lawrence et al. (2013). The purposive sample contained political reporters working at top media outlets in the United States across various media types and political reporters in the top eight states where the campaigns spent the most ad dollars as of July 2012. This was not a random sample of all journalists; it was meant to focus on those reporters most likely to be at the forefront of the political conversation during the 2012 presidential election.

2. Number of followers was not used because of a limitation in the data collection program that did not record the number of followers at the time for each of the journalists. This limitation is acceptable, given that the journalists were originally identified for inclusion in the purposive sample based on their beat, reasoning that these would be the top political reporters regardless of how popular they are on Twitter. In the smaller sample of this study, a person following the convention hashtag for news out of the conventions would likely come across many tweets by these journalists, the most frequent journalist contributors to that discussion.

\section{References}

Arant DM and Anderson JQ (2001) Newspaper online editors support traditional ethics. Newspaper Research Journal 22(4): 57-69.

Bastos MT, Raimundo RLG and Travitzki R (2013) Gatekeeping Twitter: Message diffusion in political hashtags. Media, Culture \& Society 35(2): 260-270. DOI: 10.1177/0163443712467594.

Bekafigo M and McBride A (2012) Political participation of Twitter users during the 2011 gubernatorial elections. In: APSA 2012 annual meeting, New Orleans, LA, August 2012.

Capella JN and Jamieson KH (1997) Spiral of Cynicism. New York: Oxford University Press, p. 33. Enda J (2011) Campaign coverage in the time of Twitter. American Journalism Review 33: 14-21. Farhi P (2009) The Twitter explosion. American Journalism Review 31: 26-31.

Fürsich E (2009) In defense of textual analysis. Journalism Studies 10(2): 238-252. DOI: $10.1080 / 14616700802374050$.

Hermida A (2013) \#Journalism: Reconfiguring journalism research about Twitter, one tweet at a time. Digital Journalism 1(3): 295-313. DOI: 10.1080/21670811.2013.808456.

Hermida A and Zeller F (2014) When tradition meets immediacy and interaction: The integration of social media in journalists' everyday practices. In: Annual meeting of International Communication Association, Seattle, WA, 11-26 May.

Holton AE and Lewis SC (2011) Journalists, social media, and the use of humor on Twitter. Electronic Journal of Communication 21(1 \& 2). Available at: http://www.cios.org/EJCPUBLIC/021/1/021121.html

Iyengar S, Norpoth H and Hahn KS (2004) Consumer demand for election news: The horserace sells. Journal of Politics 66(1): 157-175. DOI: 10.1046/j.1468-2508.2004.00146.x.

Jürgens P, Jungherr A and Schoen H (2011) Small worlds with a difference: New gatekeepers and the filtering of political information on Twitter. In: ACM WebSci '11, Koblenz, Germany, 14-17 June.

Kovach B and Rosenstiel T (2007) The Elements of Journalism: What Newspeople Should Know and the Public Should Expect. New York: Three Rivers Press.

Kovach B and Rosenstiel T (2010) Blur: How to Know What's True in the Age of Information Overload. New York: Bloomsbury Publishing.

Larsson AO and Moe H (2011) Studying political microblogging: Twitter users in the 2010 Swedish election campaign. New Media \& Society 14(5): 729-747. DOI: $10.1177 / 1461444811422894$.

Lasorsa DL, Lewis SC and Holton AE (2011) Normalizing Twitter. Journalism Studies 13: 19-36. DOI: $10.1080 / 1461670 x .2011 .571825$. 
Lavrusik V (2013) Best practices for journalists on Facebook. Facebook.com. Available at: https://www.facebook.com/notes/facebook-journalists/best-practices-for-journalists-on-facebook/593586440653374

Lawrence RG (2012) Campaign news in the time of Twitter: An observational study. In: APSA 2012 annual meeting, New Orleans, LA, August 2012.

Lawrence RG, Molyneux L, Coddington M, et al. (2013) Tweeting conventions: Political journalists' use of Twitter to cover the 2012 presidential campaign. Journalism Studies. Epub ahead of print 20 September 2013. DOI: 10.1080/1461670X.2013.836378.

Lindlof TR and Taylor BC (2011) Qualitative Communication Research Methods. Thousand Oaks, CA: SAGE.

Mascaro C and Goggins SP (2012) Twitter as virtual town square: Citizen engagement during a Nationally Televised Republican Primary Debate. In: APSA 2012 annual meeting. Available at: http://papers.ssrn.com/abstract $=2108682$

Molyneux L and Holton A (2014) Branding (health) journalism: Perceptions, practices, and emerging norms.DigitalJournalism.Epubahead of print30 April2014.DOI:10.1080/21670811.2014.906927.

Nolan S (2003) Journalism online: The search for narrative form in a multilinear world. In: Fifth annual digital arts and culture conference, Melbourne, VIC, Australia, 19-23 May.

Opgenhaffen M and Scheerlinck H (2014) Social media guidelines for journalists: An investigation into the sense and nonsense among Flemish Journalists. In: Annual meeting of International Communication Association, Seattle, WA, 11-26 May.

Rosen J (2006) The people formerly known as the audience. PressThink. Available at: http:// archive.pressthink.org/2006/06/27/ppl_frmr.html

Rosen J (2010) The view from nowhere: Questions and answers. PressThink. Available at: http:// pressthink.org/2010/11/the-view-from-nowhere-questions-and-answers/

Schultz I (2007) The journalistic gut feeling. Journalism Practice 1(2): 190-207. DOI: $10.1080 / 17512780701275507$.

Shifman L (2007) Humor in the age of digital reproduction: Continuity and change in internetbased comic texts. International Journal of Communication 1: 187-209.

Shoemaker PJ, Vos TP and Reese SD (2009) Journalists as gatekeepers. In: Wahl-Jorgensen K and Hanitzsch T (eds) The Handbook of Journalism Studies. New York: Routledge, pp. 73-87.

Singer JB (2005) The political j-blogger: 'Normalizing' a new media form to fit old norms and practices. Journalism 6(2): 173-198. DOI: 10.1177/1464884905051009.

Singer JB (2006) The socially responsible existentialist. Journalism Studies 7(1): 2-18. DOI: $10.1080 / 14616700500450277$.

Sonderman J (2012a) AP adds new social media guidelines on live-tweeting, friending/following sources. Poynter.org. Available at: http://www.poynter.org/latest-news/mediawire/182517/ ap-adds-new-social-media-guidelines-on-live-tweeting-friendingfollowing-sources/

Sonderman J (2012b) Should reporters' tweets and Facebook posts be edited in advance? Poynter. org. Available at: http://www.poynter.org/latest-news/mediawire/196523/should-reporterstweets-and-facebook-posts-be-edited-in-advance/\#

Vivo N and Manuel J (2013) How open are journalists on Twitter? Trends towards the end-user journalism. Communication \& Society 26(1): 93-114.

White DM (1950) The gatekeeper: A case study in the selection of news. Journalism Quarterly 27(4): 383-390.

Williams BA and Delli Carpini MX(2000)Unchained reaction: The collapse of media gatekeeping and the Clinton-Lewinsky scandal. Journalism 1(1): 61-85. DOI: 10.1177/146488490000100113.

\section{Author biography}

Logan Molyneux studies how journalists use social media and mobile technology and the effects these have on news and news audiences. 